\title{
Mô phỏng trường dòng chảy đáy trung bình tháng tại khu vực biển Bắc Trung Bộ bằng mô hình ROMS
}

\author{
Vũ Thị Vui* \\ Khoa Khi tuợng Thủy văn và Hải dương học, Trường Đại học Khoa học Tụ nhiên, ĐHQGHN, \\ 334 Nguyễn Trãi, Thanh Xuân, Hà Nội, Việt Nam \\ Nhận ngày 08 tháng 8 năm 2016 \\ Chỉnh sửa ngày 26 tháng 8 năm 2016; Chấp nhận đăng ngày 16 tháng 12 năm 2016
}

\begin{abstract}
Tóm tắt: Vấn đề xả thải gây ô nhiễm môi trường biển của công ty Formosa Hà Tĩnh đang là chủ đề nóng trong những ngày gần đây. Việc cá tầng đáy chết hàng loạt dạt vào bờ là biểu hiện đầu tiên và là một trong những sự việc đáng quan tâm nhất của sự kiện này. Dòng chảy đáy được đánh giá là nguyên nhân chính phát tán dòng độc tố từ nơi xả thải đến môi trường xung quanh, làm chết cá tầng đáy. Nghiên cứu này ứng dụng Hệ thống mô hình đại dương quy mô vùng ROMS (Regional Ocean Modeling System) để mô phỏng trường dòng chảy đáy khu vực biển Bắc Trung Bộ với mục đích: mô phỏng trường dòng chảy đáy ở khu vực này trong năm và giải thích con đường di chuyển của độc tố vào tháng 4 - thời gian bắt đầu sự kiện xả thải gây ô nhiễm biển nghiêm trọng.
\end{abstract}

Tù khóa: Dòng chảy đáy, ROMS, ô nhiễm biển, Formosa.

\section{1. Đặt vấn đề}

Vào tháng 4 năm 2016, hiện tượng rất nhiều cá biển chết hàng loạt rồi trôi dạt vào bờ tại vùng biển Vũng Âng - Hà Tĩnh gây xôn xao dư luận. Hiện tượng này sau đó lan ra vùng biển Quảng Bình, Quảng Trị, Huế. Có nơi mỗi ngày, ngư dân dọc bờ biển vớt được hàng tấn cá chết. Theo phân tích, cả nước biển lẫn nước đầm Lăng Cô - Huế đều bị ô nhiễm, nồng độ $\mathrm{PO}_{4}$ (chỉ tiêu phú dưỡng) ở tầng đáy gấp đôi chỉ số cho phép, làm tăng độ $\mathrm{pH}$ trong nước, nhiều khả năng đây là nguyên nhân làm cá chết hàng loạt. Ngoài ra tảo biển phát triển mạnh, cộng với khí độc khiến cá thiếu oxy. Từ các kết quả phân tích, khả năng cá chết do dịch bệnh đã được loại bỏ [1]. Ngày 30/6/2016, kết luận chính thức từ chính phủ Việt Nam về nguyên

ĐT.: 84-902143446

Email : vuivt@vnu.edu.vn nhân của sự việc này là do những vi phạm và sự cố trong quá trình thi công vận hành thử nghiệm tổ hợp nhà máy của công ty Formosa Hà Tĩnh [2].

Qua thực tế hầu hết cá chết dạt vào bờ là các loài cá tầng đáy, có thể thấy độc tố từ nguồn xả thải theo trường dòng chảy đáy đi xa. Dù có nhiều nguyên nhân lan truyền chất ô nhiễm, nghiên cứu này sẽ quan tâm đến nguyên nhân lan truyền độc tố bởi dòng chảy đáy. Nghiên cứu này ứng dụng Hệ thống mô hình đại dương quy mô vùng ROMS (Regional Ocean Modeling System) để mô phỏng trường dòng chảy đáy khu vực biển Bắc Trung Bộ với mục đích mang đến một cái nhìn toàn cảnh về chế độ dòng chảy đáy ở khu vực này trong năm, đồng thời giải thích con đường di chuyển của dòng độc tố theo dòng chảy đáy vào tháng 4 - thời gian bắt đầu sự việc xả thải khi công ty Formosa xả 300 tấn hóa chất nước súc rửa đường ống ra biển. 


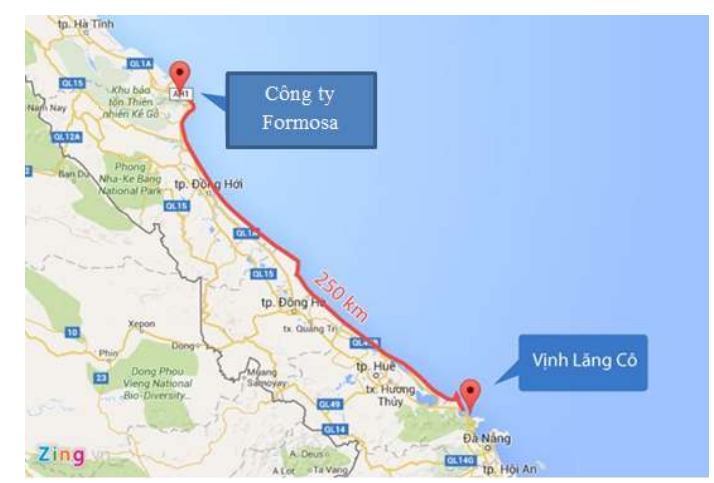

Hình 1. Vị trí công ty Formosa trên bản đồ.

\section{Giới thiệu về hệ thống mô hình ROMS}

Hệ thống mô hình đại dương quy mô vùng ROMS (Regional Ocean Modeling System) giải hệ phương trình Navier - Stokes trung bình Reynolds sử dụng xấp xỉ Boussinesq và xấp xỉ thủy tĩnh. Hệ phương trình động lực chủ đạo như sau [3]:

Trong đó:
- $u, v$ và $\Omega$ : những thành phần của vận tốc theo phương ngang $(x$ và $y)$ và theo phương thẳng đứng (theo hệ tọa độ sigma, $s$ ) tương ứng;

- $\zeta$ : độ cao nước dâng mặt thoáng trung bình sóng;

- $h$ : độ sâu của đáy biển dưới mực nước trung bình;

- $H_{Z}$ : thành phần nới rộng theo chiều thẳng đứng;

- $f$ : tham số Coriolis; $p$ : áp suất; $\rho$ : mật độ tổng cộng; $\rho_{0}$ : mật độ chuẩn;

- $g$ : gia tốc trọng trường; $v$ : hệ số nhớt phân tử.

- $C$ : yếu tố vật lý quan tâm (ví dụ: nhiệt độ, độ muối, trầm tích lơ lửng,...);

- $C_{\text {source }}$ : các thành phần nguồn $\sinh / \mathrm{mất}$ của các yếu tố vật lý.

$$
\begin{aligned}
& \frac{\partial\left(H_{Z} u\right)}{\partial t}+\frac{\partial\left(u H_{Z} u\right)}{\partial x}+\frac{\partial\left(v H_{Z} u\right)}{\partial y}+\frac{\partial\left(\Omega H_{Z} u\right)}{\partial s}-f H_{Z} v=-\frac{H_{Z}}{\rho_{0}} \frac{\partial p}{\partial x}-H_{Z} g \frac{\partial \zeta}{\partial x}-\frac{\partial}{\partial s}\left(\overline{u^{\prime} w^{\prime}}-\frac{v}{H_{Z}} \frac{\partial u}{\partial s}\right) \\
& \frac{\partial\left(H_{Z} v\right)}{\partial t}+\frac{\partial\left(u H_{Z} v\right)}{\partial x}+\frac{\partial\left(v H_{Z} v\right)}{\partial y}+\frac{\partial\left(\Omega H_{Z} v\right)}{\partial s}+f H_{Z} u=-\frac{H_{Z}}{\rho_{0}} \frac{\partial p}{\partial y}-H_{Z} g \frac{\partial \zeta}{\partial y}-\frac{\partial}{\partial s}\left(\overline{v^{\prime} w^{\prime}}-\frac{v}{H_{Z}} \frac{\partial v}{\partial s}\right) \\
& 0=-\frac{1}{\rho_{0}} \frac{\partial p}{\partial s}-\frac{g}{\rho_{0}} H_{z} \rho
\end{aligned}
$$

với phương trình liên tục:

$$
\frac{\partial \zeta}{\partial t}+\frac{\partial\left(H_{Z} u\right)}{\partial x}+\frac{\partial\left(H_{Z} v\right)}{\partial y}+\frac{\partial\left(H_{Z} \Omega\right)}{\partial s}=0
$$

và phương trình vận chuyển vô hướng:

$$
\frac{\partial\left(H_{Z} C\right)}{\partial t}+\frac{\partial\left(u H_{Z} C\right)}{\partial x}+\frac{\partial\left(v H_{Z} C\right)}{\partial y}+\frac{\partial\left(\Omega H_{Z} C\right)}{\partial s}=-\frac{\partial}{\partial s}\left(\overline{c^{\prime} w^{\prime}}-\frac{v}{H_{Z}} \frac{\partial C}{\partial s}\right)+C_{\text {source }}
$$


- Gạch ngang ở trên thể hiện trung bình thời gian và dấu nháy (') thể hiện nhiễu động rối.

Hàm $[\rho=f(C, p)]$ để xác định phương trình trạng thái.

Hệ phương trình này được khép kín bởi việc tham số hóa ứng suất Reynolds và thông lượng rối của các yếu tố vật lý:

$$
\begin{aligned}
& \overline{u^{\prime} w^{\prime}}=-K_{M} \frac{\partial u}{\partial z} ; \overline{v^{\prime} w^{\prime}}=-K_{M} \frac{\partial v}{\partial z} ; \\
& \overline{c^{\prime} w^{\prime}}=-K_{H} \frac{\partial \rho}{\partial z}
\end{aligned}
$$

Trong đó: $K_{M}$ - hệ số nhớt xoáy đối với động lượng; $K_{H}$ - hệ số khuếch tán xoáy đối với yếu tố vật lý.

Mô hình sử dụng hệ tọa độ thích ứng địa hình với lưới tính cấu trúc. Rời rạc hóa các phương trình vi phân được tiến hành: theo phương ngang: lưới tính Arakawa-C; theo phương thẳng đứng: lưới sigma.

\section{Nguồn số liệu sử dụng}

- Nguồn số liệu địa hình: bộ số liệu ETOTO2 - số liệu địa hình toàn cầu với độ phân giải 2'.

- Nguồn số liệu khí tượng: bộ số liệu COADS05 - số liệu toàn cầu về trung bình tháng các thông lượng khí tượng bề mặt biển với độ phân giải $0,5^{\circ}$. Nguồn số liệu này được dùng để thiết lập trường lực tác động cho mô hình. Do không có nguồn số liệu gió thực đo hay dự báo trong giai đoạn tháng 4/2016 của khu vực Bắc Trung Bộ, bài báo chấp nhận nguồn số liệu trung bình tháng như trên làm đầu vào cho mô hình.

- Nguồn số liệu hải văn: cơ sở dữ liệu WOA2009 - số liệu toàn cầu trung bình tháng về các yếu tố hải văn với độ phân giải $1^{0}$. Nguồn số liệu này dùng để thiết lập điều kiện biên (nghiên cứu này sử dụng các giá trị trung bình thời gian dài các yếu tố hải văn cho toàn bộ khu vực tính) và điều kiện ban đầu cho mô hình.

\section{Thiết lập và chạy mô hình}

\subsection{Chuẩn bị các file đầu vào}

Nghiên cứu sử dụng bộ công cụ ROOMSTOOLS được viết theo ngôn ngữ Matlab, với mục đích xây dựng các file đầu vào cho mô hình [4]. Các file số liệu sử dụng làm đầu vào và đầu ra trong mô hình ROMS được lưu giữ theo định dạng netCDF (*.nc).

Miền tính: kinh độ: $106^{0} \mathrm{E}-112^{0} \mathrm{E}$; vĩ độ: $15^{0} \mathrm{~N}-19^{0} \mathrm{~N}$

Lưới tính có độ phân giải $1 / 8^{0}$ (khoảng 13.5 $\mathrm{km})$, chia thành 10 tầng sigma và tăng mật độ phân bố các tầng sigma đáy.

\subsection{Các thông số thiết lập}

Nghiên cứu sử dụng phương pháp chạy mô hình thời gian dài, thời gian chạy trung bình tháng trong 2 năm, với bộ tham số được thiết lập như sau: bước thời gian: $600 \mathrm{~s}$; thời gian chạy: 2 năm; mật độ nước: $1025 \mathrm{~kg} / \mathrm{m} 3$; hệ số kéo tại đáy: $0.0003 \mathrm{~m} / \mathrm{s}$ [4]. Mô hình sử dụng điều kiện trượt tự do đối với biên cứng.

\subsection{Chay mô hìn}

Các lệnh chạy mô hình trong hệ điều hành Linux:

- Lệnh dịch mô hình: \$ bash jobcomp

- Lệnh chạy mô hình: \$ csh run_rom.csh
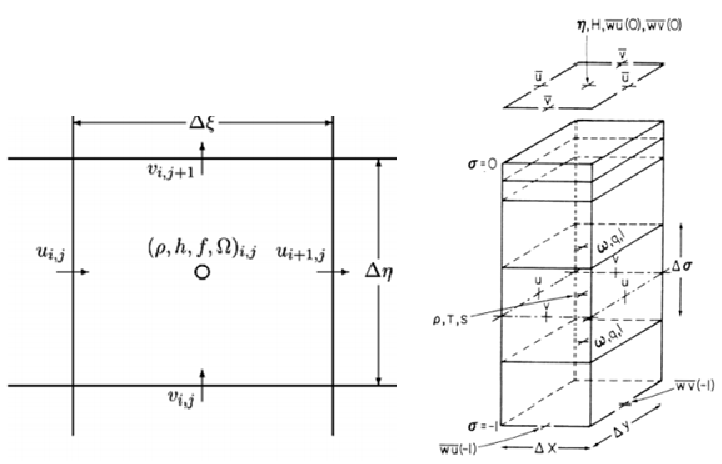

Hình 2. Hình trái: sơ đồ lưới Arakawa-C theo phương ngang. Hình phải: lưới ROMS theo phương thẳng đứng. 


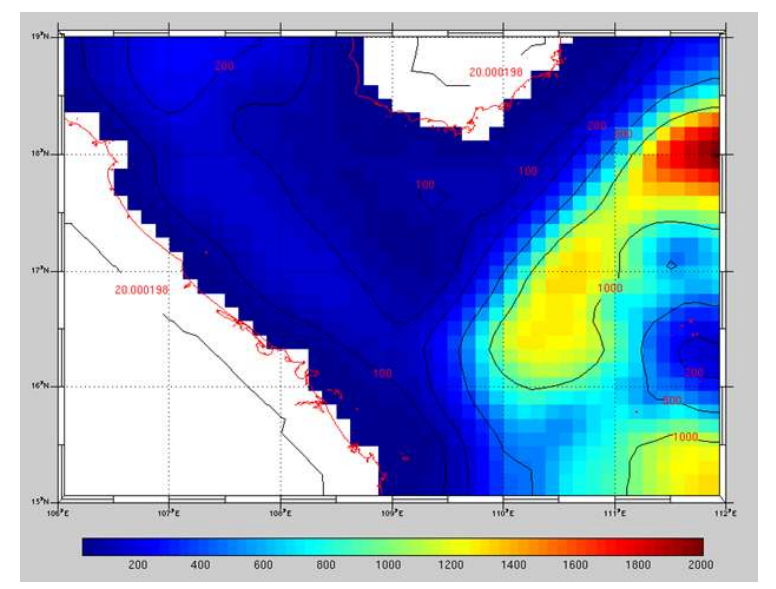

Hình 3. Địa hình khu vực biển Bắc Trung Bộ.

\section{Kết quả}

\section{* Mùa xuân (tháng 4)}

Vào mùa xuân, với đại diện tháng 4 (hình 4a), dòng chảy đáy tại khu vực biển Bắc Trung Bộ đạt tốc độ dao động trong khoảng từ dưới $0.01 \mathrm{~m} / \mathrm{s}$ đến $0.247 \mathrm{~m} / \mathrm{s}$. Dòng chảy toàn vùng phần lớn đều có tốc độ dưới $0.05 \mathrm{~m} / \mathrm{s}$, đặc biệt tại khu vực ven bờ (từ bờ ra khơi khoảng 25 $\mathrm{km})$ từ Hà Tĩnh đến Đà Nẵng, cho thấy dòng chảy đáy tại vùng này yếu, và có hướng song song bờ đi từ phía nam lên. Tuy nhiên, cách bờ một khoảng cách tầm $25-50 \mathrm{~km}$, một dòng chảy song song bờ hướng từ bắc xuống lại có giá trị lớn hơn đáng kể, với giá trị trong khoảng từ $0.05 \mathrm{~m} / \mathrm{s}$ đến $0.15 \mathrm{~m} / \mathrm{s}$. Dòng chảy ở giữa và phía đông khu vực có giá trị lớn nhất trong vùng, đặc biệt tại những nơi xuất hiện luồng dòng chảy theo hướng từ bắc xuống nam. Khu vực phía đông bắc có giá trị đạt tới cực đại (trên $0.2 \mathrm{~m} / \mathrm{s}$ ). Tồn tại một xoáy thuận tại khu vực phía đông bắc Đà Nẵng, đây được đánh giá là nguyên nhân khiến khu vực Đà Nẵng ít chịu ảnh hưởng ô nhiễm môi trường trong sự kiện xả thải.

Qua kết quả thu được, có thể giải thích con đường dòng độc tố di chuyển sau khi được xả từ Hà Tĩnh như sau: dòng độc tố di chuyển theo dòng chảy đáy gần bờ với tốc độ trung bình $(0.05 \mathrm{~m} / \mathrm{s}$ đến trên $0.1 \mathrm{~m} / \mathrm{s})$, theo hướng song song bờ, từ bắc đi xuống nam, đồng thời các dòng chảy đáy ven bờ với giá trị vận tốc nhỏ đi từ phía nam lên khiến dòng độc tố luẩn quẩn ven bờ từ Hà Tĩnh đến Huế, gây ảnh hưởng nghiêm trọng đến sinh vật và môi trường. Dòng xoáy thuận gần Đà Nẵng đã góp phần ngăn dòng độc tố gây ảnh hưởng đến môi trường biển của thành phố này, khiến vùng biển này gần như an toàn trong thời điểm ô nhiễm nặng nề nhất.

* Mùa hè (tháng 7)

Dòng chảy đáy trung bình tháng 7 (hình $4 \mathrm{~b}$ ) đại diện cho mùa hè cho thấy, vào mùa hè, trường dòng chảy đáy tại khu vực biển Bắc Trung Bộ có giá trị nằm trong khoảng từ dưới $0.01 \mathrm{~m} / \mathrm{s}$ đến $0.141 \mathrm{~m} / \mathrm{s}$, có thể nói là trường dòng chảy đáy mùa hè có giá trị thấp nhất trong năm. Dòng chảy đáy tại khu vực biển Bắc Trung Bộ có tốc độ cao có hướng từ phía nam lên là chủ yếu và đạt cực đại tại một số vùng ở giữa và phía đông bắc của khu vực (đạt giá trị trên $0.14 \mathrm{~m} / \mathrm{s}$ ). Cũng giống như mùa xuân, dòng chảy đáy tại vùng gần bờ (từ bờ ra khơi khoảng $50 \mathrm{~km}$ ) từ Hà Tĩnh đến Quảng Trị có giá trị rất nhỏ, là vùng có tốc độ dòng chảy cực tiểu trong khu vực (dưới $0.01 \mathrm{~m} / \mathrm{s}$ ). Từ gần bờ Đà Nẵng ra xa, tồn tại dòng chảy đạt tốc độ cao của khu vực trong mùa này (trên $0.12 \mathrm{~m} / \mathrm{s}$ ) có hướng song song bờ từ phía nam lên.

\section{* Mùa thu (tháng 10)}

Trong mùa thu, giá trị của dòng chảy đáy tại khu vực Bắc Trung Bộ trong hình $4 \mathrm{c}$ cũng khá nhỏ, chỉ đạt tốc độ từ dưới $0.01 \mathrm{~m} / \mathrm{s}$ đến $0.181 \mathrm{~m} / \mathrm{s}$. Vùng có dòng chảy đáy đạt được giá trị cực đại, cũng tương tự như trong mùa xuân và mùa hè, là vùng trung tâm và phía đông bắc khu vực, với tốc độ dòng chảy đạt được trên 1.8 $\mathrm{m} / \mathrm{s}$ và có hướng chủ yếu là từ bắc xuống nam. Khác với hai mùa trên, khu vực ven bờ từ Hà Tĩnh đến Đà Nẵng, dòng chảy đáy trong mùa thu tại đây không phải là giá trị thấp nhất trong khu vực, mà có các dòng chảy ven bờ có tốc độ dao động trong khoảng từ $0.02 \mathrm{~m} / \mathrm{s}$ đến 0.05 $\mathrm{m} / \mathrm{s}$, và có hướng chủ yếu từ tây bắc xuống đông nam. Vẫn tồn tại một vùng dòng chảy đáy có tốc độ cao hơn xung quanh (trên $0.05 \mathrm{~m} / \mathrm{s}$ ) và có hướng từ song song bờ từ phía nam lên, tuy nhiên tốc độ này không đạt cực đại trong khu vực như thời kỳ mùa hè. 


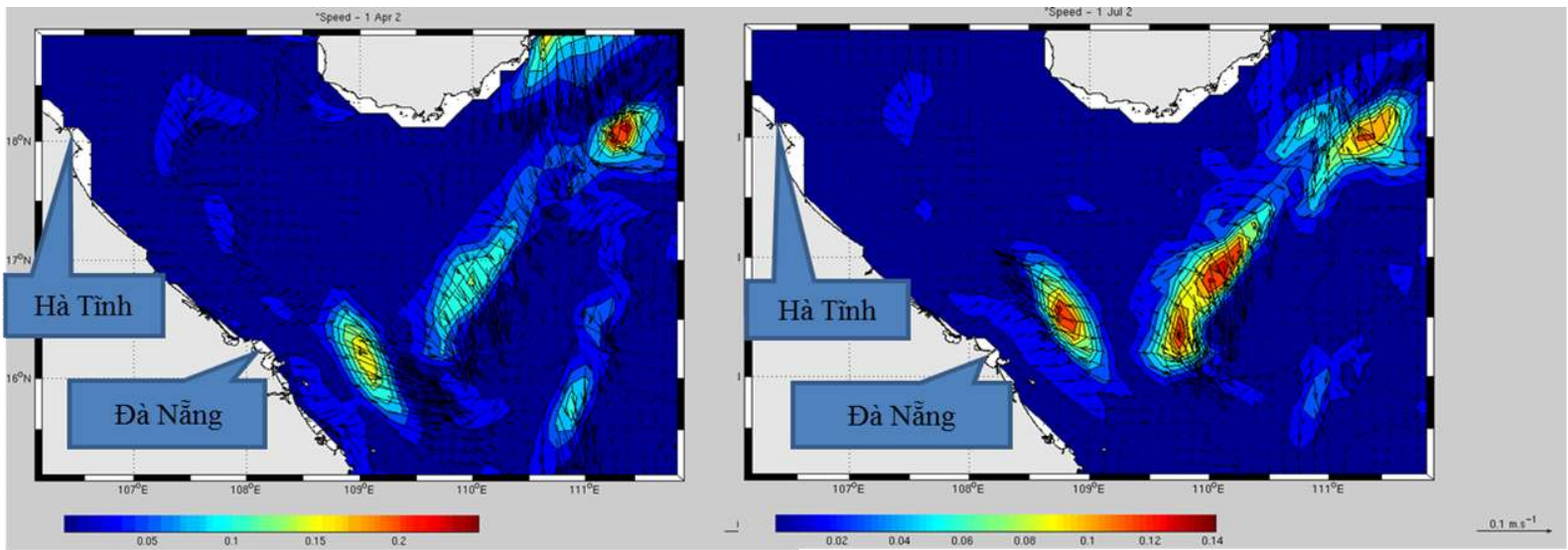

(a)

(b)

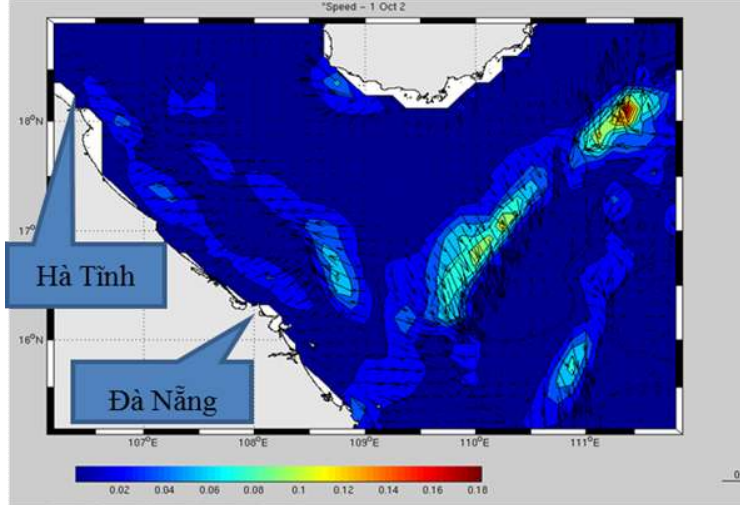

(c)

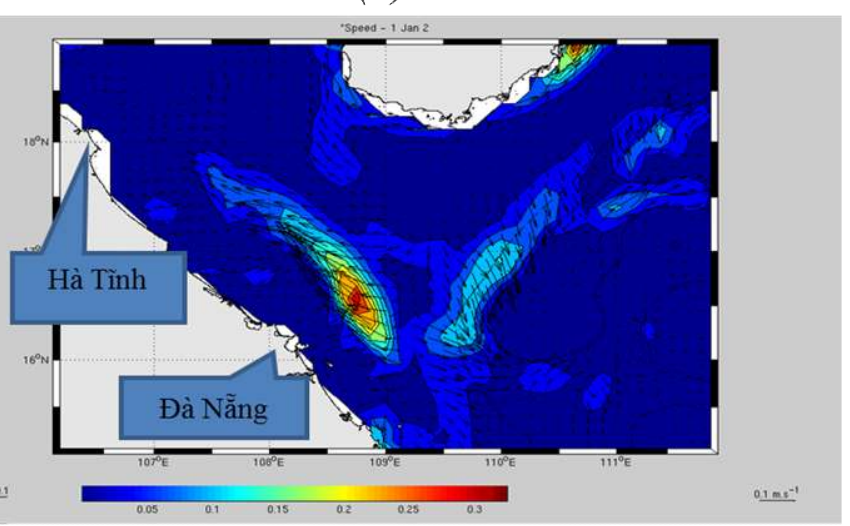

(d)

Hình 4. Trường dòng chảy đáy trung bình tháng tại khu vực biển Bắc Trung Bộ trong năm (a) - mùa xuân (tháng 4); (b) - mùa hè (tháng 7); (c) - mùa thu (tháng 10); (d) - mùa đông (tháng 1).

\section{* Mùa đông (tháng 1)}

Còn vào mùa đông, trường dòng chảy đáy tại khu vực Bắc Trung Bộ (hình $4 \mathrm{~d}$ ) có nền giá trị cao nhất trong năm, dao động từ dưới 0.01 $\mathrm{m} / \mathrm{s}$ đến $0.325 \mathrm{~m} / \mathrm{s}$. Khác với các mùa còn lại, vào thời kỳ này, dòng chảy đáy tại khu vực xa bờ Đà Nẵng là dòng có tốc độ đạt cực đại trong toàn khu vực tính (trên $0.3 \mathrm{~m} / \mathrm{s}$ ) và có hướng song song bờ từ phía nam lên. Dòng chảy ven bờ từ Hà Tĩnh đến Huế, cũng như trong mùa xuân và mùa hạ, đạt giá trị thấp nhất trong khu vực, nhưng xa bờ một khoảng cách trên $70 \mathrm{~km}$ lại tồn tại một dòng chảy song song bờ có giá trị trung bình (đạt từ $0.05 \mathrm{~m} / \mathrm{s}$ đến trên $0.3 \mathrm{~m} / \mathrm{s}$ ) theo hướng từ nam lên bắc. Dòng chảy đáy tại trung tâm khu vực có hướng từ bắc xuống nam, với tốc độ trung bình, đạt từ $0.05 \mathrm{~m} / \mathrm{s}$ đến 0.1 $\mathrm{m} / \mathrm{s}$. Tồn tại một vùng có tốc độ dòng chảy đáy đạt cực đại (trên $0.3 \mathrm{~m} / \mathrm{s}$ ) tại phía đông bắc của khu vực, hướng song song bờ từ nam lên bắc.

\section{Kết luận}

Các kết quả mô phỏng từ mô hình cho thấy, tốc độ dòng chảy trong năm tại khu vực Bắc Trung Bộ khá nhỏ, chỉ đạt cực đại đến 0.325 $\mathrm{m} / \mathrm{s}$. Giá trị trường dòng chảy đáy trong mùa đông đạt giá trị cao nhất trong năm còn vào 
mùa hè thì giá trị này lại nhỏ nhất năm. Kết quả tính cũng góp phần giải thích về quá trình độc tố di chuyển theo dòng chảy đáy trong thời điểm Formosa xả thải gây ô nhiễm môi trường biển nghiêm trọng tại khu vực này hồi đầu tháng 4 năm 2016.

Với tốc độ dòng chảy đáy nhỏ như vậy, phải rất lâu nữa môi trường - sinh thái khu vực biển Bắc Trung Bộ mới trở lại như trước, mà phải trong điều kiện ngừng xả thải. Còn trong thực tế, bất chấp các thảm kịch hiển hiện ngay trước mắt, các công ty ven biển vẫn tiếp tục xả ra biển hàng chục, hàng trăm tấn hóa chất độc hại mỗi ngày mà chưa có biện pháp quản lý rõ ràng, hiệu quả từ các cơ quan chức năng.

\section{Lời cảm ơn}

Nghiên cứu này được tài trợ bởi Trường Đại học Khoa học Tự nhiên trong đề tài mã số TN.16.22. Tác giả xin cảm ơn sự tài trợ này.

\section{Tài liệu tham khảo}

[1] Bách khoa toàn thư mở wikipedia về công ty Formosa Hà Tĩnh: https://vi.wikipedia org/ wiki/ Formosa_V\%C5\%A9ng_\%C3\%81ng;

[2] Bài báo công bố nguyên nhân cá chết của chính phủ Việt Nam ngày 30/6/2016: http:/vietnamnet.vn/vn/thoi-su/chinhtri/313134/formosa-lam-ca-chet-boi-thuong-500trieu-usd.html;

[3] D.B. Haidvogel, H. Arango, W.P. Budgell, B.D. Cornuelle, E. Curchitser, E. Di Lorenzo, K. Fennel, W.R. Geyer, A.J. Hermann, L. Lanerolle, J. Levin, J.C. McWilliams, A.J. Miller, A.M. Moore, T.M. Powell, A.F. Shchepetkin, C.R. Sherwood, R.P. Signell, J.C. Warner, J. Wilkin, "Ocean forecasting in terrainfollowing coordinates: Formulation and skill assessment of the Regional Ocean Modeling System", Journal of Computational Physics 227 (2008) 3595-3624, 2008;

[4] Pierrick Penven, Gildas Cambon, Thi-Anh Tan, Patrick Marchesiello and Laurent Debreu, "ROMS AGRIF / ROMSTOOLS User's Guide", Institut de Recherche pour le D'eveloppement (IRD), France, 2010.

\title{
Simulating the Monthly Average of the Bottom Current Field in the North Central of Vietnam Sea Area by the Model ROMS
}

\author{
Vu Thi Vui \\ Faculty of Hydro-Meteology \& Oceanography, VNU University of Science, \\ 334 Nguyen Trai, Hanoi, Vietnam
}

\begin{abstract}
The issue of discharge polluting the marine environment of the company Formosa Ha Tinh is a hot topic in recent days. The bottom dead fishes is the first expression and is one of the most concerned facts of this event. The bottom current is considered the main reason to emit the toxic from the source to the surrounding environment, killing the bottom fishes. This research applicated the model system ROMS (Regional Ocean Modeling System) to simulate the current field of the ocean bottom in the North central of Vietnam sea area with the aim of: simulating the bottom current field in this area during the year and explain the diffusive path of the toxin in April - the start time of the discharge causing the serious marine pollution.
\end{abstract}

Keywords: Bottom current, ROMS, marine pollution, Formosa. 